\title{
KOMUNIKASIRINGKAS \\ KEANEKARAGAMAN JENIS KEONG (GASTROPODA) DI PANTAI UJUNG KELOR, BATUNAMPAR, DAN GUNUNG LINUS TELUK EKAS, LOMBOK TIMUR (NTB)
}

\author{
Pandoe Prahoro*' dan Anthony Sisco P."
}

\begin{abstract}
ABSTRAK
Keong (gastropoda) merupakan salah satu sumber daya laut yang dapat dikonsumsi sebagaimana halnya sumber daya laut lainnya seperti ikan dan udang, khususnya sebagai bahan makanan bagi masyarakat pesisir pantai

Studi mengenai keanekaragaman jenis keong telah dilakukan di perairan Teluk Ekas, Lombok Timur, pada bulan Oktober dan November 1995 sebagai bagian dari kegiatan inventarisasi sumber daya laut secara umum. Pengambilan sampel dilakukan di tiga lokasi, yaitu Ujung Kelor, Batunampar, dan Gunung Linus yang masing-masing terdiri atas sepuluh petak dengan tiga kali pengulangan, dengan mempergunakan metode transek kuadran.

Dari hasil inventarisasi tersebut diperoleh informasi bahwa kelimpahan jenis gastropoda di perairan Ujung Kelor adalah 30,3 ind $/ \mathrm{m}^{2}$. Batunampar $46,82 \mathrm{ind} . / \mathrm{m}^{2}$, dan Gunung Linus 17,3 ind. $/ \mathrm{m}^{2}$. Kerapatan jenis pada masing-masing lokasi tersebut $9,63 \mathrm{ind} . / \mathrm{m}^{2}, 15,28 \mathrm{ind} . / \mathrm{m}^{2}$, dan 5,83 ind $/ \mathrm{m}^{2}$, dan keanekaragaman jenis $\left(\mathrm{H}^{\prime}\right)$ berturut-turut adalah 0,$888 ; 0,743$; dan 0,893
\end{abstract}

ABSTRACT: Diversity of gastropoda in the coastal area of Ujung Kelor, Batunampar, and Gunung Linus Ekas Bay, East Lombok. By: Pandu Prahoro and Anthony Sisco P.

Gastropoda is a group of marine biota. Some of them are economically important and most of them provide high and valuable food resources.

As part of a research inventory of marine resources, a study on diversity of marine gastropoda resources has been conducted in Ekas Bay, East Lombok. The avtiviities was carried out in October and November 1995. Observation were performed in three spots and each spot was devided into ten transec blocks. Transec Kuadran Method was used in the study and sampling was done in three replicants.

It was found that the abundance of gastropoda in Ujung Kelor, Batunampar, and Gunung Linus located were $30.3 \mathrm{ind} . / \mathrm{m}^{2} ; 46.82 \mathrm{ind} . / \mathrm{m}^{2}$; and $17.3 \mathrm{ind} . / \mathrm{m}^{2}$ respectively. Species density in Ujung Kelor. Batunampar, and Gunung Linus were $9.63 \mathrm{ind} . / \mathrm{m}^{2} ; 15.28 \mathrm{ind} . / \mathrm{m}^{2}$; and $5.83 \mathrm{ind} . / \mathrm{m}^{2}$ respectively. The diversity were 0.888 in Ujung Kelor; 0.743 in Batunampar; and 0.893 in Gunung Linus.

KEYWORDS : density, abundance, diversity, gastropoda.

\section{PENDAHULUAN}

Moluska terdiri atas lima kelas besar yaitu : 1) Amfineura, 2) Gastropoda, 3) Pelesipoda, 4) Cefalopoda, dan 5) Skafopoda. Dari kelima kelas tersebut tiga kelas di antaranya mempunyai arti ekonomis cukup penting yaitu Gastropoda (keong), Pelesipoda (kerang/kepah), dan Cefalopoda (cumi, sotong, dan gurita) (Nontji, 1987)

Keong (Gastropoda) merupakan sumber daya laut yang kurang populer untuk dikonsumsi dibandingkan dengan sumber daya ikan dan udang. Bila dilihat dari jumlah jenis biota yang hidup di dasar perairan. Indonesia merupakan salah satu perairan yang kaya akan jumlah serta jenis gastropodanya (Salvat dalam Subani et al., 1989).

Di perairan Teluk Ekas, Lombok Timur (NTB), keong banyak dimanfaatkan oleh masyarakat setempat untuk keperluan pangan. Oleh karena dapat dimanfaatkan, maka permasalahan yang timbul adalah seringkali terjadi pemanfaatan yang tidak terkendali dan bijaksana sehingga dapat merusak kelestarian sumber daya keong tersebut.

Dari pengamatan ini diharapkan dapat memberikan informasi yang berguna tentang keadaan sumber daya keong yang meliputi kelimpahan, kepadatan, dan keanekaragaman jenisnya di perairan Teluk Ekas. Hasil informasi ini diharapkan dapat dikembangkan

Peneliti pada Balai Penelitian Perikanan Laut 
lebih lanjut untuk dijadikan salah satu dasar bagi langkah-langkah dalam menjaga kelestarian jenis keong akibat tekanan penangkapan yang terusmenerus dan membuka peluang budi daya bagi pengembangan jenis-jenis keong yang bernilai ekonomi

\section{BAHAN DAN METODE}

Penelitian ini dilaksanakan pada bulan Oktober dan November 1995 di perairan Teluk Ekas, Lombok Timur NTB yang merupakan bagian dari inventarisasi sumber daya laut secara umum. Pengambilan sampel dilakukan di tiga stasiun pada lahan/hamparan pasang surut. Stasiun 1 terletak di kawasan Ujung Kelor, stasiun 2 terletak di kawasan Batunampar dan stasiun 3 terletak di kawasan Gunung Linus. Kondisi dari ketiga stasiun tersebut merupakan hamparan pasir. Metode yang digunakan adalah transek kuadran. Tiap stasiun pengamatan diambil 3 transek yang berukuran masingmasing $10 \mathrm{~m}^{2}$ dan dilakukan tiga kali pengulangan pada saat keadaan surut. Sedimen yang diambil dengan mempergunakan grab disaring dengan saringan yang berukuran diameter $0,3 \mathrm{~cm}$. Seluruh jenis gastropoda yang tersaring diidentifikasi dengan berpedoman pada buku Habe \& Kasuge (1976), Dharma (1988), dan Sabelli (1979). Untuk melihat keanekaragaman jenis keong di Ujung Kelor, Batunampar, dan Gunung Linus, data primer yang diperoleh telah dianalisis untuk menentukan kerapatan, kelimpahan dan keanekaragaman jenis.

\section{ANALISIS DATA}

\section{Kerapatan dan Kelimpahan Jenis}

Untuk melihat keberadaan satu jenis gastropoda dengan jenis yang lain pada suatu daerah pengamatan dapat dipergunakan analisis kerapatan jenis dan kelimpahan jenis, yang dihitung menurut Cox (1976). Metode penghitungan yang dipergunakan ialah:

Kerapatan Jenis $i(D)=\frac{\mathrm{Jml} \text { total individu jenis } i}{\mathrm{Jml} \text { luas semua petak }}$

Kelimpahan jenis $i(A)=\frac{\mathrm{Jml} \text { total individu jenis } i}{\mathrm{Jml} \text { luas petak di mana terdapat jenis } i}$

\section{Keanekaragaman Jenis (H')}

Nilai keanekaragaman jenis dihitung dengan mempergunakan metode Shannon Weaner dalam Poole (1974) ialah

$$
H^{\prime}=-\sum_{i}^{s} p i \ln p i \quad p i=\frac{N i}{N}
$$

dengan

$\mathrm{S}=\sum$ spesies
$\mathrm{i}=$ urutan $\sum$ spesies
$\mathrm{Ni}=\sum$ individu tiap spesies
$\mathrm{N}=\sum$ keseluruhan spesies
Indeks Keragaman Shannon : $\mathrm{E}=\mathrm{H}^{\prime} / \mathrm{H}_{\text {maks }}$ dengan
$\mathrm{E}=$ Indeks Keragaman
$\mathrm{H}_{\text {maks }}=$ In S

\section{HASIL DAN BAHASAN}

\section{Kelimpahan dan Kerapatan Jenis Keong (Gastropoda)}

Kelimpahan dan kerapatan jenis keong selain banyak terdapat pada daerah terumbu karang dan pasir, juga banyak ditemukan dalam jumlah yang besar di perairan dangkal pada kedalaman 1-5 m yang banyak mendapat cahaya matahari (Nybakken, 1988).

Pada hasil pengamatan di perairan Teluk Ekas ditemukan 62 jenis keong dengan jumlah 2.791 ind./ $90 \mathrm{~m}^{2}$. Jenis yang paling banyak terdapat pada hamparan pasang surut di kawasan Batunampar yaitu 1.406 ind. $/ 30 \mathrm{~m}^{2}$, Ujung Kelor 871 ind $/ 30 \mathrm{~m}^{2}$, dan Gunung Linus 514 ind. $/ 30 \mathrm{~m}^{2}$. Jenis Gari costulata paling banyak terdapat di lokasi pengamatan yaitu 1.506 ind.$/ 90 \mathrm{~m}^{2}$, Tellinides tunarensis 242 ind $.190 \mathrm{~m}^{2}$, dan Clypeomrus sp. 184 ind $/ 90 \mathrm{~m}^{2}$.

Banyaknya keberadaan ketiga jenis keong ini ditunjang oleh faktor lingkungan yang sangat mendukung, hal ini terlihat bahwa cukup luasnya hamparan pantai berpasir putih serta serpihan dan pecahan batu karang. Keadaan ini merupakan habitat yang baik bagi kehidupan ketiga jenis keong tersebut. Faktor adanya tekanan lingkungan seperti pengambilan jenis keong yang berlebihan untuk keperluan pangan sangat menentukan keberadaan jenis keong tertentu.

Faktor nilai ekonomis (ukuran, rasa, dan khasiatnya) dapat juga mempengaruhi keberadaan suatu jenis keong, karena semakin bernilai ekonomis maka pemanfaatannya juga akan semakin besar. Sedangkan untuk jenis keong yang kurang mempunyai nilai ekonomis maka pemanfaatannya juga akan berkurang. Tingkat pemanfaatan inilah yanc paling besar pengaruhnya terhadap keberadaan suatu jenis keong. Pemanfaatan yang tidak berwawasan lingkungan dan bijaksana akan mempercepat kepunahan suatu jenis keong. Untuk itu 
perlu adanya lanigkah-langkah menjaga kelestariannya dari tekanan penangkapan yang terus-menerus dan perlu juga adanya langkah-langkah pembudidayaan jenis keong yang bernilai ekonomis tersebut. Pada saat pengamatan diketahui pemanfaatan sumber daya keong di perairan Teluk Ekas sudah dilakukan oleh masyarakat setempat untuk pemenuhan kebutuhan pangan sehari-hari.

Jenis-jenis keong yang sering dimanfaatkan dan dikosumsi oleh masyarakat setempat untuk keperluan bahan makanan sehari-hari adalah dari famili Cardiidae (Vasticardium sp.), famili Donatidae (Donax sp.), famili Lucinidae (Codakia sp.), famili Mitridae (Srigatella teloscopium, Pterygia fenestrata), famili Mactridae (Austromactra sp.) famili Neritidae (Neritina sp.), famili Strombidae (Strombus sp.), dan famili Siphonariidae (Siphonaria sirius)

\section{Kelimpahan Jenis Keong (Gastropoda)}

Kelimpahan jenis yang terbesar di ketiga lokasi perairan tersebut adalah jenis Gari costulata yaitu 13,9 ind. $/ \mathrm{m}^{2}$ di Ujung Kelor; 28,9 ind. $/ \mathrm{m}^{2}$ di Batunampar dan 7,4 ind $/ \mathrm{m}^{2}$ di Gunung Linus (Tabel 1). Tingginya

Tabel 1. Kelimpahan dan kerapatan jenis keong (Gastropoda) di Ujung Kelor, Batunampar, dan Gunung Linus Teluk Ekas, Lombok Timur NTB (ind. $/ \mathrm{m}^{2}$ )

Table 1. Abundance and density of Gastropoda in Ujung Kelor, Batunampar, and Gunung Linus at Ekas Bay East Lombok NTB (ind. $/ \mathrm{m}^{2}$ )

\begin{tabular}{|c|c|c|c|c|c|c|}
\hline \multirow{2}{*}{$\begin{array}{l}\text { Jenis } \\
\text { (Species) }\end{array}$} & \multicolumn{3}{|c|}{$\begin{array}{l}\text { Kelimpahan } \\
\text { (Abundance) }\end{array}$} & \multicolumn{3}{|c|}{$\begin{array}{l}\text { Ke rapatan } \\
\text { (Density) }\end{array}$} \\
\hline & \multicolumn{3}{|c|}{ Ujung kelor Batu nampar Gunung linus } & \multicolumn{3}{|c|}{ Ujung kelor Batu nampar Gunung linus } \\
\hline (1) & (2) & (3) & (4) & (5) & (6) & (7) \\
\hline \multicolumn{7}{|l|}{ Family Baccinidae } \\
\hline Enzinopsis sp. & 0.1 & 0.2 & 0.03 & 0.02 & 0.01 & 0.01 \\
\hline $\begin{array}{l}\text { Enzinopsis histrio } \\
\text { Family Conidae }\end{array}$ & 0.6 & \multicolumn{4}{|c|}{ Family Conidae } & - \\
\hline Conus sp. & 0.4 & 1.2 & 0.3 & 0.1 & 0.4 & 0.1 \\
\hline Lithoconus eberneus & 0.03 & & - & 0.01 & - & - \\
\hline Virroconus suturalis & 1.3 & 0.3 & 0.2 & 0.04 & 0.1 & 0.01 \\
\hline Rhizoconus malaccanus & - & 0.03 & - & - & 0.01 & - \\
\hline \multicolumn{7}{|l|}{ Family Cerithidae } \\
\hline Contumax petrosus & - & 0.7 & - & - & 0.02 & - \\
\hline Cardetamera flandana & - & - & 0.03 & - & - & 0.01 \\
\hline Clypeomrus sp. & 1.6 & 2.8 & 1.8 & 0.5 & 0.9 & 0.6 \\
\hline Cerithium polygonum & - & 0.03 & - & - & 0.01 & - \\
\hline Certhidae obtusa & - & 0.03 & 0.1 & - & 0.01 & 0.04 \\
\hline Rhinoclavis sp. & - & 0.01 & - & - & 0.02 & - \\
\hline $\begin{array}{l}\text { Semivertagus alveolus } \\
\text { Family Costellariidae }\end{array}$ & 0.2 & 0.1 & 0.3 & 0.1 & 0.04 & 0.1 \\
\hline $\begin{array}{l}\text { Zierliana waldemarii } \\
\text { Family Columbellidae }\end{array}$ & 0.1 & - & - & 0.03 & - & - \\
\hline Pyrene llacteoides & - & - & 0.03 & - & - & 0.01 \\
\hline $\begin{array}{l}\text { Pictocolumbella ocellata } \\
\text { Family Cardiidae }\end{array}$ & 0.03 & 0.7 & 0.2 & 0.01 & 0.2 & 0.1 \\
\hline Carcullum cardissa & & - & 0.2 & - & - & 0.01 \\
\hline $\begin{array}{l}\text { Verticardium sp. } \\
\text { Family Cypraeidae }\end{array}$ & 0.1 & 0.1 & - & 0.02 & 0.02 & - \\
\hline $\begin{array}{l}\text { Monetaria sp. } \\
\text { Family Donatidae }\end{array}$ & 0.03 & 0.03 & 0.03 & 0.01 & 0.01 & 0.01 \\
\hline Donax sp & 0.4 & 0.6 & 0.4 & 0.1 & 0.2 & 0.1 \\
\hline $\begin{array}{l}\text { Tellinides tunarensis } \\
\text { Family Glycymeridae }\end{array}$ & 3.6 & 3.7 & 0.8 & 1.2 & 1.2 & 0.3 \\
\hline Melaxinaea subpectinifor & - & - & 0.03 & - & - & 0.01 \\
\hline $\begin{array}{l}\text { Tucetonasp. } \\
\text { Family Limidae }\end{array}$ & 0.4 & 0.7 & 0.1 & 0.1 & 0.2 & 0.03 \\
\hline Littarina $x y z a z$ & - & 0.03 & - & - & 0.01 & - \\
\hline
\end{tabular}




\begin{tabular}{|c|c|c|c|c|c|c|}
\hline (1) & (2) & (3) & (4) & (5) & (6) & (7) \\
\hline \multicolumn{7}{|l|}{ Family Littorinidae } \\
\hline Nedilittorinasp. & 0.1 & - & 0.03 & 0.02 & - & - \\
\hline Nodilittorina sp. & - & 0.03 & - & - & 0.01 & - \\
\hline \multicolumn{7}{|l|}{ Family Lucinidae } \\
\hline Gari costulata & 13.9 & 28.9 & 7.4 & 4.6 & 9.6 & 2.5 \\
\hline Codakaisp. & - & 0.1 & - & - & 0.02 & - \\
\hline \multicolumn{7}{|l|}{ Family Mitridae } \\
\hline Chrysane vexyllum & 0.03 & - & 0.2 & 0.01 & - & 0.01 \\
\hline Chrysane Iungubris & 0.03 & - & - & 0.01 & - & - \\
\hline Srigatella teloscopium & 0.1 & - & - & 0.04 & - & - \\
\hline Pterygia fenestrata & - & - & 0.1 & - & - & 0.03 \\
\hline \multicolumn{7}{|l|}{ Family Mactridae } \\
\hline Austromactra sp. & 0.7 & 2.1 & - & 0.2 & 0.7 & - \\
\hline \multicolumn{7}{|l|}{ Family Neritidae } \\
\hline Neritina sp. & 0.03 & 0.03 & - & 0.01 & 0.01 & - \\
\hline Family Naticidae & & & & & 0.02 & \\
\hline Natica sp. & 0.1 & 0.1 & - & 0.02 & & - \\
\hline Notocholis sp. & - & 0.1 & - & - & 0.02 & - \\
\hline Polinices sp. & 0.03 & 0.03 & - & 0.01 & 0.01 & - \\
\hline \multicolumn{7}{|l|}{ Family Neritopsidae } \\
\hline Olivia sp. & - & 0.03 & - & - & 0.01 & - \\
\hline \multicolumn{7}{|l|}{ Family Nassariidae } \\
\hline Niotha rehusta & 0.2 & 0.03 & 0.1 & 0.1 & 0.01 & 0.03 \\
\hline Niotha fissilabris & 0.2 & - & 0.03 & 0.1 & - & 0.01 \\
\hline Plicarcularia mangeloides & 0.2 & 0.5 & - & 0.1 & 0.2 & - \\
\hline Scabranossa harrida & 0.03 & - & - & 0.01 & - & - \\
\hline \multicolumn{7}{|l|}{ Family Planaxidae } \\
\hline Planaxis sp. & 0.03 & 0.03 & 0.03 & 0.01 & 0.01 & 0.01 \\
\hline Planaxis sulcatus & - & 0.2 & - & - & 0.1 & - \\
\hline Quoiya sp. & 0.1 & 0.03 & 0.03 & 0.04 & 0.01 & 0.01 \\
\hline Supplanaxis nigra & 0.2 & - & - & 0.1 & - & - \\
\hline \multicolumn{7}{|l|}{ Family Pyramidellidae } \\
\hline Milda ventricosa & - & 0.1 & - & - & 0.03 & - \\
\hline Longehoous uburnea & - & 0.03 & - & - & 0.01 & - \\
\hline \multicolumn{7}{|l|}{ Family Strombidae } \\
\hline Strombus sp. & 0.2 & - & - & 0.1 & - & - \\
\hline \multicolumn{7}{|l|}{ Family Siphonariidae } \\
\hline Shiphonaria sirius & - & 0.03 & - & - & 0.01 & - \\
\hline \multicolumn{7}{|l|}{ Family Tellinidae } \\
\hline Pharaonella sp. & 2.9 & 0.4 & 1.2 & 0.9 & 0.1 & 0.4 \\
\hline Psamotellina ambiqua & 0.03 & - & - & 0.01 & - & - \\
\hline \multicolumn{7}{|l|}{ Family Trochidae } \\
\hline Monodonta sp. & - & 0.03 & - & - & 0.01 & - \\
\hline Salsipotens speciosum & - & - & 0.2 & - & - & 0.1 \\
\hline Tectus sp. & - & 0.03 & - & - & 0.01 & - \\
\hline \multicolumn{7}{|l|}{ Family Turridae } \\
\hline Lophiotoma sp. & - & 0.03 & - & - & 0.01 & - \\
\hline \multicolumn{7}{|l|}{ Family Terebridae } \\
\hline Dip/omeriza spectabilis & - & 0.01 & - & - & 0.02 & - \\
\hline \multicolumn{7}{|l|}{ Family Veneridae } \\
\hline Meretrix sp. & 0.5 & 1.2 & 2.2 & 0.2 & 0.4 & 0.7 \\
\hline Paphia sp. & - & - & 0.03 & - & - & 0.01 \\
\hline Liochoncho sp. & 0.5 & 0.09 & 0.2 & 0.2 & 0.3 & 0.1 \\
\hline \multicolumn{7}{|l|}{ Tidak teridentifikasi } \\
\hline Unidentified & 1.3 & 0.5 & 0.7 & 0.4 & 0.2 & 0.2 \\
\hline Total & 30.3 & 46.8 & 17.3 & 9.63 & 15.19 & 5.83 \\
\hline
\end{tabular}


kelimpahan jenis keong tersebut selain menunjukkan bahwa kondisi lingkungan di lokasi pengamatan sangat mendukung untuk kehidupan jenis keong tersebut, juga diduga bahwa jenis keong ini belum dimanfaatkan karena belum bernilai ekonomis Dengan demikian keberadaannya dapat mendominasi suatu perairan. Faktor pemangsa juga mempengaruhi keberadaannya karena semakin sedikit predator alaminya maka semakin besar keberadaannya di suatu habitat. Kelimpahan total di perairan Ujung Kelor adalah 30,3 ind. $/ \mathrm{m}^{2}$ sedangkan di Batunampar 46,8 ind $/ \mathrm{m}^{2}$ dan di Gunung Linus 17,3 ind $/ \mathrm{m}^{2}$.

Pada saat pengamatan diketahui bahwa masyarakat setempat hanya memanfaatkan keong sebagai bahan makanan mereka sehari-hari dan belum memanfaatkannya untuk diperjualbelikan atau untuk bahan industri pakaian (pembuatan kancing)

\section{Kerapatan Jenis Keong (Gastropoda)}

Kerapatan jenis yang tertinggi di ketiga lokasi perairan tersebut adalah jenis Gari costulata yaitu 4,6 ind $/ \mathrm{m}^{2}$ di Ujung Kelor; 9,6 ind $/ \mathrm{m}^{2}$ di Batunampar dan 2,5 ind $/ \mathrm{m}^{2}$ di Gunung Linus (Tabel 1). Faktor yang mempengaruhi dimungkinkan karena adanya kompetisi ruang seperti pakan, tempat hidup, dan predator. Oleh karena banyaknya jenis keong yang sudah dapat dimanfaatkan dan dikonsumsi dari selain jenis keong ini maka ruang hidupnya semakin besar dan mendominasi. Kerapatan total di ketiga lokasi perairan ini ialah Ujung Kelor 9,63 ind $/ \mathrm{m}^{2}$ sedangkan di Batunampar 15,28 ind $/ \mathrm{m}^{2}$ dan di Gunung Linus 5.83 ind. $\mathrm{m}^{2}$

\section{Keanekaragaman Jenis $(\mathrm{H} \phi)$}

Keanekaragaman jenis keong (gastropoda) di tiga lokasi perairan tidak menunjukkan nilai yang sangat berbeda, seperti yang disajikan pada Tabel 2. Hal ini disebabkan karena kondisi perairan di ketiga lokasi tersebut relatif sama sehingga hampir semua jenis terdapat di ketiga lokasi perairan tersebut. Keanekaragaman jenis keong di perairan Ujung Kelor sebanyak 35 jenis dengan $H^{\prime}=0,888$; di Batunampar 41 jenis dengan $H^{\prime}=0,743$ dan di Gunung Linus 29 jenis dengan $H^{\prime}=0,893$. Dengan demikian keanekaragaman jenis keong yang tersebar di lokas perairan Batunampar lebih beragam dibandingkan dengan di perairan Ujung Kelor dan Gunung Linus. Akan tetapi pada ketiga lokasi perairan tersebut tidak terlihat perbedaan jenis yang menyolok dan penyebaran jenis dari jenis-jenis keong tersebut relatif merata di ketiga lokasi perairan

Berdasarkan Tabel 2 diketahui bahwa nilai keanekaragaman jenis $\left(H^{\prime}\right)$ di ketiga lokasi berkisar antara 0,88-0,89 yang berarti bahwa perbedaan keanekaragaman jenis di ketiga daerah tersebut sangat kecil. Kecilnya keanekaragaman diduga karena adanya tekanan ekologi yang sangat kuat yaitu berupa pengambilan jenis-jenis keong yang beriebihan untuk dimanfaatkan sebagai bahan makanan seharihari oleh masyarakat setempat. Menurut Odum (1977) bila nilai keanekaragamanan jenis kurang dari 1,0 maka keanekaragaman jenis kecil karena adanya tekanan ekologi yang sangat kuat. Apabila nilai keanekaragaman jenis antara 1,0-3,0 maka keanekaragaman jenis sedang karena adanya tekanan ekologi yang sedang, dan apabila nilai keanekaragaman jenis lebih dari 3,0 maka keanekaragaman jenis tinggi sehingga terjadi keseimbangan ekosistem.

Sedangkan untuk nilai keseragaman (S) di ketiga lokasi pada Tabel 2 berkisar antara 0,25-0,26. Ini berarti bahwa perairan di ketiga lokasi tersebut mempunyai konsentrasi dominansi jenis yang cukup rendah. Hal ini sesuai dengan pendapat Odum (1977) yang menyatakan bahwa apabila nilai keseragaman mendekati nilai 1 maka populasi menunjukkan keseragaman dan bila keseragaman mendekati 0 maka berarti hanya ada satu atau beberapa jenis yang mendominasi populasi di perairan tersebut

\section{KESIMPULAN}

1. Di perairan Ujung Kelor terdapat 35 jenis keong (gastropoda) dengan kelimpahan jenis 30,3 ind./ $\mathrm{m}^{2}$ dan kerapatan jenis 9,63 ind $/ \mathrm{m}^{2}$, di perairan Batunampar terdapat 41 jenis dengan kelimpahan jenis 46,82 ind. $/ \mathrm{m}^{2}$ dan kerapatan jenis 15,28 ind /

Tabel 2. Indeks Keanekaragaman Jenis (H') dan Keragaman (S) Gastropoda di Ujung Kelor, Batunampar dan Gunung Linus, perairan Teluk Ekas, Lombok Timur (NTB)

Table 2. Diversity Index and State of Gastropoda in Ujung Kelor, Batunampar, and Gunung Linus at Ekas Bay, East Lombok (NTB)

\begin{tabular}{lcc}
\multicolumn{1}{c}{ Stasiun } & $\mathrm{H}^{\prime}$ & $\mathrm{S}$ \\
\hline Ujung Kelor & 0.888 & 0.25 \\
Batunampar & 0.743 & 0.19 \\
Gunung Linus & 0.893 & 0.26 \\
\hline
\end{tabular}


$\mathrm{m}^{2}$, sedangkan di perairan Gunung Linus terdapat 29 jenis dengan kelimpahan jenis 17,3 ind $/ \mathrm{m}^{2}$ dan kerapatan jenis 5,83 ind $/ \mathrm{m}^{2}$.

2. Keanekaragaman jenis di ketiga lokasi perairan tidak menunjukkan perbedaan yang relatif menyolok yaitu untuk di perairan Ujung Kelor 0,888, di perairan Batunampar 0,743, dan perairan Gunung Linus 0,893.

3. Jenis keong (gastropoda) yang dominan terdapat di perairan Ujung Kelor, Batunampar, dan Gunung Linus adalah jenis Gari costulata.

4. Pemanfaatan keong (gastropoda) di perairan Teluk Ekas oleh masyarakat setempat hanya untuk kebutuhan bahan makanan sehari-hari.

\section{DAFTAR PUSTAKA}

Cox, G. W. 1967 Laboratory Manual of General Ecology. W. M. C.Brown Co Publ. Dubuque lowa. 35 pp.

Dharma, B.1988. Siput dan Kerang Indonesia (Indonesian Shells / dan II) Penerbit PT. Sarana Graha Jakarta. $27 \mathrm{pp}$.

Habe, T. And Kasuge. 1976. Shells of the World Color Vol II. The Tropical Pacific. 193 pp.

Nontji, A. 1987. Laut Nusantara Penerbit Gramedia. Jakarta. $161 \mathrm{pp}$.
Nybakken, J. W. 1988. Biologi Laut, Suatu Pendekatan Ekologis. Penerbit Gramedia JKT 325 pp.

Odum, E. P. 1971. Fundamental of Ecology $3^{\text {rd }} \mathrm{ed}$. Philadelphia W.B. Saunders Company. 574 pp.

Poole, R V. 1974. An Introduction to Quantitative Ecology. Mc. Graw Hill Series in Population Biology. Inc. All Right Reserved Printers in United States of America California. $76 \mathrm{pp}$

Sabelli, B. 1979. Guide to Shells. Edited Femberg H.S The America Museum of Natural History Published by Simmons and Schuster. $511 \mathrm{pp}$.

Soekarno, M. H., M. K. Moosa and P. Darsono. 1981. Terumbu Karang Indonesia, Sumber Daya, Permasalahan dan Pengelolaannya. LON-LIPI JKT. $31 \mathrm{pp}$.

Subani, W. et al. 1989. Potensi dan Penyebaran Sumber Daya Moluska dan Teripang. Direktorat Jendral Perikanan, Jakarta. 26 pp.

Sunarno. 1994. Perbandingan Kehadiran, Kerapatan, dan Kelimpahan Kima (Tridacna) di Pulau Kayu Angin Bira dan Pulau Pramuka Taman Nasional Laut Kepulauan Seribu. Skripsi Sarjana Biologi Fakultas Biologi Universitas Nasional Jakarta. 29 pp

Webb. W. F. 1945. Hand book for Shells Collectors Ilustrations and Description of Marine Species Foreign to the USA. St. Petterburg 6 Florida $235 \mathrm{pp}$. 
Lampiran 1. Jumlah individu keong (gastropoda) di Ujung Kelor, Batunampar, dan Gunung Linus di perairan Teluk Ekas, Lombok Timur (NTB)

Annex 1. Species of gastropoda in Ujung Kelor, Batunampar, and Gunung Linus at Ekas Bay, East Lombok (NTB)

\begin{tabular}{|c|c|c|c|}
\hline Jenis (Species) & Ujung Kelor & Batunampar & Gunung Linus \\
\hline$(1)$ & (2) & (3) & (4) \\
\hline \multicolumn{4}{|l|}{ Family Baccinidae } \\
\hline Enzinopsis sp. & 2 & 7 & 1 \\
\hline Enzinopsis histrio & 19 & & - \\
\hline \multicolumn{4}{|l|}{ Family Conidae } \\
\hline Conus sp. & 11 & 36 & 9 \\
\hline Lithoconus eberneus & 1 & & - \\
\hline Virroconus suturalis & 4 & 9 & 5 \\
\hline Rhizoconus malaccanus & - & 1 & - \\
\hline Texilla spectrum & - & - & 9 \\
\hline \multicolumn{4}{|l|}{ Family Cerithiidae } \\
\hline Contumax petrosus & - & 20 & - \\
\hline Cardetamera flandana & - & - & 1 \\
\hline Clypeomrus sp. & 48 & 83 & 53 \\
\hline Cerithium polygonum & & 1 & - \\
\hline Certhidae obtusa & - & 1 & - \\
\hline Rhinoclavis $\mathrm{sp}$ & & 2 & - \\
\hline Semivertagus alveolus & 6 & 4 & 8 \\
\hline \multicolumn{4}{|l|}{ Family Costellariidae } \\
\hline Zierliana waldemari & 3 & - & - \\
\hline \multicolumn{4}{|l|}{ Family Columbellidae } \\
\hline Pyrene lacteoides & - & - & 1 \\
\hline Pictocolumbella ocellata & 1 & 21 & 5 \\
\hline \multicolumn{4}{|l|}{ Family Cardiidae } \\
\hline Carcullum cardissa & - & - & 7 \\
\hline Vasticardium sp. & 2 & 2 & - \\
\hline \multicolumn{4}{|l|}{ Family Cypraeidae } \\
\hline Monetaria sp. & 1 & 1 & 1 \\
\hline \multicolumn{4}{|l|}{ Family Donatidae } \\
\hline Donax sp. & 11 & 18 & 13 \\
\hline Tellinides tunarensis & 107 & 112 & 23 \\
\hline \multicolumn{4}{|l|}{ Family Glycymeridae } \\
\hline Melaxinaea subpectiniformis & - & - & 1 \\
\hline Tucetona sp. & 13 & 22 & 3 \\
\hline \multicolumn{4}{|l|}{ Family Limidae } \\
\hline Littarina xyzaz & & 1 & - \\
\hline \multicolumn{4}{|l|}{ Family Littorinidae } \\
\hline Nedilittorina sp. & 2 & - & - \\
\hline Nodilittorina sp. & - & 1 & - \\
\hline \multicolumn{4}{|l|}{ Family Lucinidae } \\
\hline Gari costulata & 417 & 868 & 221 \\
\hline Codakia sp. & - & 2 & - \\
\hline \multicolumn{4}{|l|}{ Family Mitridae } \\
\hline Chrysane vexyllum & 1 & - & - \\
\hline Chrysane lungubris & 1 & - & - \\
\hline
\end{tabular}




\begin{tabular}{|c|c|c|c|}
\hline (1) & (2) & (3) & (4) \\
\hline Srigatella teloscopium & 4 & - & - \\
\hline Pterygia fenestrata & - & - & 3 \\
\hline \multicolumn{4}{|l|}{ Family Mactridae } \\
\hline Austramactra sp. & 21 & 62 & - \\
\hline \multicolumn{4}{|l|}{ Family Neritidae } \\
\hline Neritina $\mathrm{sp}$ & 1 & 1 & - \\
\hline \multicolumn{4}{|l|}{ Family Naticidae } \\
\hline Natica $\mathrm{sp}$ & 2 & 2 & - \\
\hline Notocholis sp. & - & 2 & - \\
\hline Polinices sp. & 1 & 1 & - \\
\hline \multicolumn{4}{|l|}{ Family Neritopsidae } \\
\hline Olivia $\mathrm{sp}$ & - & 1 & - \\
\hline \multicolumn{4}{|l|}{ Family Nassariidae } \\
\hline Niotha rehusta & 6 & 1 & 3 \\
\hline Niotha fissilabris & 6 & - & 1 \\
\hline Plicarcularia mangeloides & 5 & 14 & - \\
\hline Scabranossa harrida & 1 & - & - \\
\hline \multicolumn{4}{|l|}{ Family Planaxidae } \\
\hline Planaxis sp. & 1 & 1 & 1 \\
\hline Planaxis sulcatus & - & 5 & - \\
\hline Quoiyo sp. & 4 & 1 & 1 \\
\hline Supplanaxis nigra & 5 & - & - \\
\hline \multicolumn{4}{|l|}{ Family Pyramidellidae } \\
\hline Milda ventricosa & - & 3 & - \\
\hline Longehaus uburnea & - & 1 & - \\
\hline \multicolumn{4}{|l|}{ Family Strombidae } \\
\hline Strombus sp. & 5 & - & - \\
\hline \multicolumn{4}{|l|}{ Family Siphonariidae } \\
\hline Siphonaria sirius & - & 1 & - \\
\hline \multicolumn{4}{|l|}{ Family Telinidae } \\
\hline Pharaonella sp. & 88 & 12 & 37 \\
\hline Psamotellina ambiqua & 1 & - & - \\
\hline \multicolumn{4}{|l|}{ Family Trochidae } \\
\hline Monodonta sp. & - & 1 & - \\
\hline Salsipotens speciosum & - & - & 5 \\
\hline Tectus sp. & - & 1 & - \\
\hline \multicolumn{4}{|l|}{ Family Turridae } \\
\hline Lophiotoma sp. & - & 1 & - \\
\hline \multicolumn{4}{|l|}{ Family Terebridae } \\
\hline Diplomeriza spectabilis & - & 2 & - \\
\hline \multicolumn{4}{|l|}{ Family Veneridae } \\
\hline Meritrix sp. & 16 & 37 & 66 \\
\hline Paphia sp. & - & - & 1 \\
\hline Liochoncho sp. & 14 & 28 & 5 \\
\hline \multicolumn{4}{|l|}{ Tidak teridentifikasi } \\
\hline Unimodified & 40 & 16 & 20 \\
\hline Keanekaragaman Jenis $\left(H^{\prime}\right)$ & 0,888 & 0,743 & 0,893 \\
\hline Keseragaman Jenis (S) & 0,25 & 0,19 & 0,26 \\
\hline
\end{tabular}

